\section{More on assisted suicide}

I agree with Drs. Flegel and Fletcher that we must speak up now regarding assisted suicide and euthanasia. ${ }^{1}$

On July 15, 2012, in the Carter decision, a provincial judge rejected the Supreme Court's Rodriguez precedent and purported to legalize assisted suicide and euthanasia throughout Canada. ${ }^{2}$ I am not a lawyer, but a plain reading of the decision reveals questionable assumptions and a lack of understanding of the needs of patients.

The linchpin of the decision is that suicide is not illegal in Canada and is therefore a right. ${ }^{2}$ But Canadian laws strive to prevent suicide and even authorize forcible treatment for those who are suicidal. The judge in the Carter case admits that "suicide and attempts at suicide are serious public health problems that governments are trying to address." Thus, the idea that suicide is a right that society must assist with, as long as it is not a crime, is confused.

The judge then declares that the law prohibiting assisted suicide discriminates against people who are too disabled to kill themselves. She also speculates that the law might prompt the plaintiff to commit suicide sooner, while able, which would shorten her life. ${ }^{2}$

This Orwellian reasoning, presuming a right to die based on the right to (unshortened) life, ignores the fact that anyone, including the plaintiff, who commits suicide will suffer from a shortened life. How many years of life would Canadians lose if a legal assisted suicide risk lurked constantly in home and hospital?

A friend of mine recently died from a brain tumour. He said that when he first received the diagnosis he might have opted for assisted suicide, had it been available. Two years later, he was an activist against legalization. In the last article he wrote, he states “[Canada's] laws exist to protect me and people like me from abuse when we are at our lowest and most vulnerable."’3

As a family doctor, I see elder abuse. Sadly, a desire for money or an inheritance is often involved. Worse, the vic- tims protect the predators. An older woman knew that her son was robbing her blind and lied to protect him. Why? Perhaps family loyalty, shame or fear that confronting the abuser would cost love and care.

Predators take their victims to the bank and to the lawyer for a new will. With legal assisted suicide, the next stop could be the doctor's office for a lethal prescription. How are we going to detect victimization? A troubling survey, ${ }^{4}$ one of several which uncovers nonconsented euthanasia deaths in foreign jurisdictions, failed to alarm the judge in Carter v. Canada. ${ }^{2}$

\section{Will Johnston MD}

Chair, Euthanasia Prevention Coalition of British Columbia, Vancouver, BC

\section{References}

1. Flegel K, Fletcher J. Choosing when and how to die: Are we ready to perform therapeutic homicide? CMAJ 2012;184:1227.

2. Carter v. Canada (Attorney General), 2012 BCSC 886. No. S112688.

3. Coppard J. From Afghanistan to activist against assisted suicide: "These things are worth fighting for." Vancouver (BC): Euthanasia Prevention Coalition; 2012. Available: www.epcbc.ca/2012/06 /from-afghanistan-to-activist-against.html\#more (accessed 2012 July 17).

4. Chambaere K, Bilsen J, Cohen J, et al. Physicianassisted deaths under the euthanasia law in Belgium: a population-based survey. CMAJ 2010 182: 895-901

CMAJ 2012. DOI:10.1503/cmaj.112-2086

\section{Perspectives on consent}

Robert Byrick, president of the College of Physicians and Surgeons of Ontario, wrote a letter to $C M A J,{ }^{1}$ titled "Consent requirements for pelvic examinations." In his letter he states that, "express consent of the patient must be obtained (whether the patient is conscious during the examination). The policy also clearly states that if, for any reason, express consent cannot be obtained, the examination cannot be performed." I have 2 questions for Dr. Byrick based on the following scenario: a 23-year-old female patient presents in an emergency department with acute lower abdominal pain, is in shock and unconscious and unable to give consent for a pelvic exam. Is your policy flexible enough to permit a pelvic exam under these circumstances? And if the patient died while the doctor was diligently searching for the next of kin to give consent for the pelvic exam, could the family sue the doctor, and the College of Physicians and Surgeons of Ontario for negligence for exercising "the authority to hold physicians accountable" for a poorly worded or inflexible policy?

\section{Ian A. Cameron MD}

Professor, Department of Family Medicine, Dalhousie University, Halifax, NS

\section{Reference}

1. Byrick R. Consent requirements for pelvic examinations. CMAJ 2012;184:1393.

CMAJ 2012. DOI:10.1503/cmaj.112-2087

\section{The author responds}

The College policy "Professional Responsibilities in Postgraduate Medical Education"1 relates to examinations performed solely for educational purposes and specifically states that "an examination is defined as 'solely' educational when it is unrelated to or unnecessary for patient care or treatment." For example, if an examination for the purposes of a clinical demonstration was going to be performed while a patient was under sedation, consent would need to be obtained prior to the examination. This does not apply to the scenario posed by Dr. Cameron $^{2}$ as the policy does not relate to situations where the examination is necessary for patient care or treatment.

\section{Robert Byrick MD}

President, College of Physicians and Surgeons of Ontario, Toronto, Ont.

\section{References}

1. The College of Physicians and Surgeons of Ontario. Professional responsibilities in postgraduate medical education. Toronto (ON): The College; 2011.

2. Cameron IA. Perspectives on consent [letter] CMAJ 2011;184:2018.

CMAJ 2012. DOI:10.1503/cmaj.112-2088

We at the Canadian Medical Protective Association (CMPA) read with interest the CMAJ article, "Informed consent for clinical treatment." We were disap- 